\title{
Role of Colesevelam in Combination Lipid-Lowering Therapy
}

\author{
Michael R. Jones $\cdot$ Oliseyenum M. Nwose
}

Published online: 3 August 2013

(c) The Author(s) 2013. This article is published with open access at Springerlink.com

\begin{abstract}
Hyperlipidemia is associated with an increased risk of cardiovascular events; reducing low-density lipoprotein cholesterol (LDL-C), the primary target for cholesterol-lowering therapy, lowers the risk for such events. Although bile acid sequestrants were the first class of drugs to show a mortality benefit related to LDL-C lowering, statins are now considered first-line pharmacological therapy for reducing LDL-C levels because of their potency and their remarkable record of successful outcomes studies. Nevertheless, a substantial proportion of patients do not achieve LDL-C goals with statin monotherapy. In addition, because of adverse effects (primarily myopathy), some patients may be unwilling to use or unable to tolerate statin therapy at all or may not tolerate a full therapeutic statin dose. Also, statins may increase risk of new-onset diabetes in patients at high risk for diabetes. Thus, there remains a need for other lipid-lowering drugs to be used in combination with or in place of statins. The purpose of this article is to review available data from the literature on the use of colesevelam, a second-generation bile acid sequestrant, in combination with other lipid-lowering agents. Colesevelam has been studied in combination with statins, niacin, fibrates, and ezetimibe (including some three-drug combinations). An additive reduction in LDL-C was seen with all combinations. Other observed effects of colesevelam in combination with other lipid-lowering drugs include reductions in apolipoprotein (apo) B (with statins, fibrates,
\end{abstract}

M. R. Jones

Port St. Lucie, FL, USA

O. M. Nwose ( $\square)$

Daiichi Sankyo, Inc., 2 Hilton Court,

Parsippany, NJ 07054, USA

e-mail: onwose@dsi.com ezetimibe, statin plus niacin, or statin plus ezetimibe) and high-sensitivity C-reactive protein (with statins), and increases in apo A-I (with statins, ezetimibe, or statins plus niacin). Triglyceride levels remained relatively unchanged when colesevelam was combined with statins, fibrates, ezetimibe, or statin plus ezetimibe, and decreased with the triple combination of colesevelam, statin, and niacin. Colesevelam offset the negative glycemic effects of statins and niacin in subjects with insulin resistance or impaired glucose tolerance. Colesevelam was generally well tolerated when added to other lipid-lowering therapies in clinical trials, with gastrointestinal effects such as constipation being the predominant adverse events. Since colesevelam is not absorbed and works primarily in the intestine, it has a low potential for systemic metabolic drug-drug interactions with other drugs. Colesevelam has been shown to not interact with the lipid-lowering drugs lovastatin and fenofibrate; where interaction may be anticipated, separating dosing times by $4 \mathrm{~h}$ reduces the impact of any interaction. Available data confirms that colesevelam has additive cholesterol-lowering effects when used in combination with other lipid-lowering therapies. Furthermore, in some patient populations, the additional glucose-lowering effect of colesevelam may be beneficial in offsetting hyperglycemic effects of other lipid-lowering drugs.

\section{Introduction}

Patients with hyperlipidemia have an increased risk of stroke, myocardial infarction, cardiovascular disease, and other complications [1]. The Third Report of the National Cholesterol Education Program Expert Panel on Detection, Evaluation, and Treatment of High Blood Cholesterol in Adults (ATP-III) identified low-density lipoprotein 
cholesterol (LDL-C) as the primary target for cholesterollowering therapy [1]. Based on ATP-III and a subsequent update, LDL-C goals are defined as $<160 \mathrm{mg} / \mathrm{dL}$ for individuals with $0-1$ risk factor, $<130 \mathrm{mg} / \mathrm{dL}$ for those with $\geq 2$ risk factors, and $<100 \mathrm{mg} / \mathrm{dL}$ for those with coronary heart disease (CHD) or CHD risk equivalents, with an optional goal of $<70 \mathrm{mg} / \mathrm{dL}$ for those with both CHD and additional risk factors $[1,2]$.

Prior to the advent of statins, bile acid sequestrants were recommended as first-line therapy for lowering LDL-C levels [3]. Early studies with cholestyramine and colestipol showed reductions in total cholesterol [4-9] that were later shown to be primarily attributable to reduced levels of LDL-C [10]. The combination of bile acid sequestrants and niacin was found to reduce LDL-C and increase highdensity lipoprotein cholesterol (HDL-C) levels [11, 12]. Importantly, a clinical trial with the bile acid sequestrant cholestyramine, the Lipid Research Clinics Coronary Primary Prevention Trial, was the first to demonstrate that a reduction in LDL-C levels (mean reduction $12 \%$ vs. placebo) translated into a significant reduction in cardiovascular risk over 7 years $(19 \%$ reduction in risk of CHD death or nonfatal myocardial infarction; $p<0.001$ ) [13].

\subsection{Statin Monotherapy: Strengths and Limitations}

Inhibitors of 3-hydroxy-3-methylglutaryl coenzyme A reductase (statins) are considered first-line pharmacological therapy for lowering LDL-C levels [1]. The West of Scotland Coronary Prevention Study demonstrated that the reduction in LDL-C with pravastatin (mean reduction $26 \%$ vs. no change with placebo) was accompanied by a significant reduction in cardiovascular risk $(31 \%$ reduction in risk of CHD death or nonfatal myocardial infarction; $p<0.001$ ) over an average follow-up period of 4.9 years among men with hypercholesterolemia and no history of myocardial infarction [14]. A similar reduction in cardiovascular risk in the secondary prevention setting was demonstrated by the Scandinavian Simvastatin Survival Study; a reduction in LDL-C of $35 \%$ (vs. $+1 \%$ with placebo) was accompanied by a $30 \%$ reduction in total mortality $(p=0.0003)$ and a $34 \%$ reduction in risk of major coronary events $(p<0.00001)$ over a median of 5.4 years of follow-up [15]. Statins also reduce triglyceride levels (7-30 \%) and increase HDL-C levels (5-15\%) [1].

However, a substantial proportion of patients (up to approximately $50 \%$ ) do not achieve LDL-C goals with statin monotherapy [16-21]. Another consideration is that some patients may be unwilling to use or unable to tolerate statin therapy because of adverse effects. The most wellknown type of adverse effect associated with statin therapy is myopathy, the effects of which can range in severity from asymptomatic increases in creatine kinase, through myalgias and muscle weakness, up to the rare but potentially fatal rhabdomyolysis [22, 23]. Some patients may not be able to tolerate maximal doses of statins, as adverse effects associated with statin therapy are often dose related $[24,25]$. A meta-analysis of statin trials showed that the use of intensive-dose statin therapy, compared with moderate-dose therapy, was associated with a significant increase in risk of any adverse event (odds ratio 1.44; $95 \%$ confidence interval $[\mathrm{CI}] 1.33-1.55 ; p<0.001)$ and risk of adverse events leading to treatment discontinuation (1.28; $1.18-1.39 ; p<0.001)$ [26]. In the Study of the Effectiveness of Additional Reductions in Cholesterol and Homocysteine (SEARCH), patients with a history of myocardial infarction receiving simvastatin $80 \mathrm{mg}$ had an increased risk of myopathy ( 0.9 vs. $0.03 \%$; relative risk $26.6,95 \%$ CI $6.5-109.3 ; p<0.0001)$ and rhabdomyolysis (0.1 vs. $0.0 \%$ ) compared with patients taking simvastatin $20 \mathrm{mg} /$ day [27]. Based on findings such as these, the US Food and Drug Administration placed limitations on the use of the 80-mg dose of simvastatin [23]. The results of the Cholesterol Treatment Trialists' meta-analysis published in 2012 suggest that the present guidelines may need to be reconsidered to include statin therapy for patients at low risk of vascular disease, based on their observation that the statin-associated benefit of a reduction in major vascular events exceeded any known hazards of statin therapy [28]. However, a recent retrospective cohort analysis by Mansi et al. [29] concluded that further adverse event studies are required, based on their finding that musculoskeletal conditions, arthropathies, injuries (dislocations, strains, and sprains), and pain are more common in statin users than in non-users. They concluded that "the full spectrum of statins' musculoskeletal adverse events may not be fully explored, and further studies are warranted, especially in physically active individuals" [29].

More recently, concerns have been raised with regard to statins having unfavorable glycemic effects. A number of studies have shown an increased risk of developing newonset diabetes associated with statin therapy [30-32], particularly in individuals with multiple risk factors for developing diabetes [33]. A dose effect has also been shown for this increased risk with statins [31, 34]. In a study in individuals at risk of developing type 2 diabetes who were participating in lifestyle interventions, increased fasting glucose levels were seen in statin users but not in non-users [35]. Such findings have led to US labeling for statins being updated to include warnings regarding increased risk of elevated blood sugar levels. While shortterm cardiovascular benefit may outweigh long-term diabetes risk for many patients, for patients who are already at risk of developing type 2 diabetes, clinicians may be concerned about prescribing a lipid-lowering therapy that may further increase diabetes risk. 


\subsection{Combination Therapy}

Combination therapy with other lipid-lowering agents has the potential for additive reductions in LDL-C, although additional cardiovascular benefit has not been demonstrated. A meta-analysis indicated that the combination of statins with fibrates or ezetimibe was not associated with better clinical outcomes than high-dose statin monotherapy; limited outcomes data were available for combinations of statins with other lipid-lowering agents [36]. Recent American Diabetes Association guidelines indicate that combination lipid-lowering therapy is not broadly recommended because of the lack of demonstrated incremental cardiovascular benefit over that achieved with statins [37]. Similarly, the current European Society of Cardiology/European Atherosclerosis Society guidelines for the management of dyslipidemia recommend considering combination therapy in high-risk individuals, those with very high LDL-C levels, or in patients who are either statin-intolerant or unable to tolerate higher statin doses [38]. However, a systematic review of agents used to treat dyslipidemias in clinical practice concluded that complementary effects of agents other than statins might substantially provide clinical benefits in not only individuals with severe dyslipidemias but in other patients as well. The author recommended that multiple drug combinations should be more widely used to potentially get more people to lipoprotein goals, even in light of the fact that cardiovascular outcomes data are lacking for such combination therapies [39].

\subsection{Purpose of this Review}

Although statins have superseded bile acid sequestrants as first-line lipid-lowering agents, bile acid sequestrants such as the second-generation agent colesevelam can be used in combination with a range of other classes of lipid-lowering agents. The purpose of this article is to review available data from the literature on the use of colesevelam in combination with other lipid-lowering agents and report the efficacy of these combination therapies in improving the lipid profile as well as non-lipid parameters. The tolerability and safety of colesevelam in combination therapy is also briefly discussed. Clinical outcomes data for colesevelam, either as monotherapy or in combination with other agents, were not included in this review, as the literature search did not find any published outcomes data.

\subsection{Methodology}

This review is based on clinical trials reporting the lipidlowering effects of colesevelam used in dual or triple combination with other lipid-lowering agents, including statins, fibrates, niacin, and ezetimibe. Clinical study publications were identified from MEDLINE literature searches using the search terms 'colesevelam' and either 'atorvastatin,' 'fluvastatin,' 'lovastatin,' 'pitavastatin,' 'pravastatin,' 'simvastatin,' 'rosuvastatin,' 'gemfibrozil,' 'fenofibrate,' 'clofibrate,' 'ezetimibe,' 'niacin,' or 'nicotinic acid.' Studies reporting lipid-lowering efficacy results were individually selected manually from the search results. These search results included the lipid disorders hypercholesterolemia, familial hypercholesterolemia, mixed hyperlipidemia, and dyslipidemia, as well as the comorbidities diabetes, insulin resistance, and atherosclerosis.

\section{Efficacy}

\subsection{Colesevelam in Dual Combinations}

Studies evaluating colesevelam as part of a dual lipidlowering combination regimen have been conducted with various statins, a fibrate, niacin, and ezetimibe.

\subsubsection{Colesevelam Plus Statins}

Colesevelam has been studied in combination with atorvastatin, lovastatin, rosuvastatin, and simvastatin in patients with hypercholesterolemia. The combination of colesevelam with a statin was more effective in lowering LDL-C than the corresponding monotherapies (Fig. 1) [4042]. Notably, in a randomized, double-blind, placebocontrolled, parallel-design, multicenter, 8-week study evaluating the efficacy of colesevelam $3.75 \mathrm{~g} /$ day when coadministered with atorvastatin $10 \mathrm{mg} /$ day in 94 patients with moderate hypercholesterolemia, the LDL-C reduction achieved with colesevelam plus atorvastatin (48\%) was not significantly different from that observed with atorvastatin $80 \mathrm{mg} /$ day (53\%) [41]. A prospective, randomized, open-label, blinded endpoint study that assessed changes in lipid profile as a secondary endpoint in 40 patients assigned to colesevelam $3.75 \mathrm{~g} /$ day plus rosuvastatin $5 \mathrm{mg} /$ day combination therapy or rosuvastatin $10 \mathrm{mg} /$ day monotherapy for 3 months showed that similar reductions in LDL-C were also observed with colesevelam $3.75 \mathrm{~g} /$ day plus rosuvastatin $5 \mathrm{mg} /$ day and rosuvastatin $10 \mathrm{mg} /$ day alone in patients with hypercholesterolemia and insulin resistance ( $-45 \%$ for both) [43]. It should be noted that the small sample size and open-label design were listed as study limitations and could have potentially introduced bias into the study's findings.

The addition of colesevelam to existing statin therapy has been shown to have an incremental benefit on LDL-C levels. A pooled analysis of three randomized, doubleblind, placebo-controlled, parallel, 6-week clinical trials 

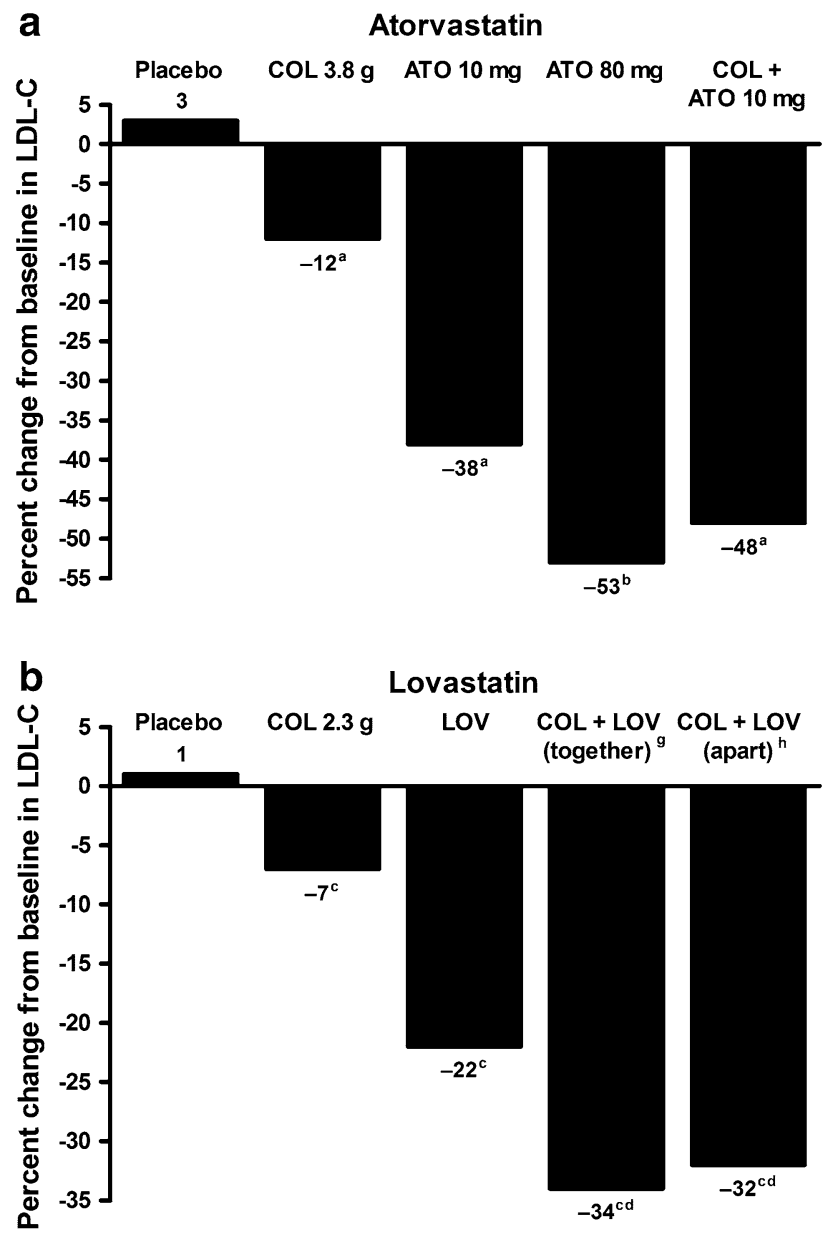

C

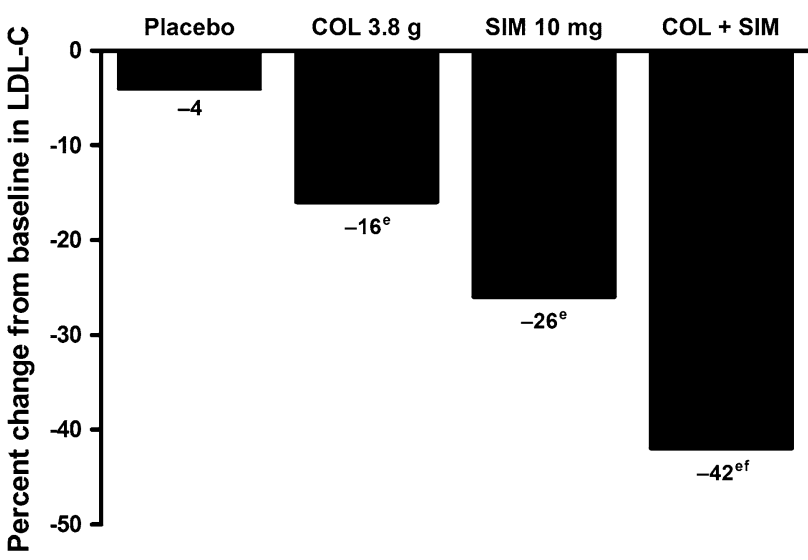

evaluated the efficacy of adding colesevelam $3.75 \mathrm{~g} /$ day or placebo to stable existing statin therapy (atorvastatin, pravastatin, or simvastatin) in 204 patients with primary hypercholesterolemia. Study results showed a significant incremental reduction in LDL-C with the addition of colesevelam to statins $(-9.2 \% ; p \leq 0.001)$ [44]. Similarly, in a post hoc analysis of pooled data from three double-blind, placebo-controlled studies in which
4 Fig. 1 Percent reductions from baseline in low-density lipoprotein cholesterol (LDL-C) in studies evaluating colesevelam (COL) administered in combination with a statin: a COL and atorvastatin (ATO) alone and in combination [41], b COL and lovastatin (LOV) alone and in combination [40], and c COL and simvastatin (SIM) alone and in combination [42]. ${ }^{\mathrm{a}} p<0.01$ for all between-group comparisons. ${ }^{\mathrm{b}} p<0.01$ for all between-group comparisons except $\mathrm{COL}+\mathrm{ATO} 10 \mathrm{mg} /$ day vs. ATO $80 \mathrm{mg} /$ day $(p=0.07) .{ }^{\mathrm{c}} p<0.05$ vs. placebo. ${ }^{\mathrm{d}} p<0.05$ vs. each monotherapy. ${ }^{\mathrm{e}} p<0.0001$ vs. placebo. ${ }^{\mathrm{f}} p \leq 0.001$ vs. each monotherapy. ${ }^{\mathrm{g}} \mathrm{COL}$ and LOV given together at dinner. ${ }^{\mathrm{h}} \mathrm{COL}$ given at dinner and LOV administered at bedtime. ATO panel adapted from Hunninghake et al. [41], with permission from Elsevier. LOV panel reproduced from Davidson et al. [40], Copyright (C 2001 Wiley Periodicals, Inc., with permission from John Wiley \& Sons, Inc. SIM panel adapted from Knapp et al. [42], with permission from Elsevier

colesevelam $3.75 \mathrm{~g} /$ day or placebo was added to existing metformin-, sulfonylurea-, or insulin-based therapy in patients $(N=301,437$, and 280 , respectively) with type 2 diabetes, among patients receiving statins at baseline, the addition of colesevelam led to a significant reduction in LDL-C $(-15.6 \% ; p<0.0001)$ [45].

Levels of HDL-C significantly increased with both colesevelam plus atorvastatin $10 \mathrm{mg} /$ day and with atorvastatin $80 \mathrm{mg} /$ day alone, but the increase was numerically greater for the combination (11 vs. $5 \%$ ). This may reflect a paradoxical decrease in the effect on HDL-C at higher doses of atorvastatin [41].

Changes in LDL-C were accompanied by reductions in apolipoprotein (apo) B. Significant $(p<0.05)$ reductions from baseline in apo B were seen with colesevelam monotherapy $(-10 \%)$, atorvastatin $10 \mathrm{mg} /$ day $(-32 \%)$ and $80 \mathrm{mg} /$ day $(-46 \%)$, and colesevelam plus atorvastatin $10 \mathrm{mg} /$ day $(-38 \% ; p<0.05$ for differences among treatment groups) [41]. Similarly, in a multicenter, randomized, double-blind, placebo-controlled trial to determine the lipid-lowering efficacy of colesevelam coadministered with simvastatin in 251 patients with primary hypercholesterolemia, there was a significantly greater reduction from baseline in apo B with colesevelam plus simvastatin than with either agent as monotherapy ( -33 vs. $-14 \%$ and $-20 \%$, respectively; $p<0.05$ ) [42]. Both dosing regimens of colesevelam plus lovastatin achieved reductions in apo B (-24\% for both) that exceeded those of the individual components $(-3$ and $-16 \%$, respectively) [40].

Increases in apo A-I were also observed with active treatment [40-42]. In the atorvastatin study, significant $(p<0.05)$ increases from baseline in apo A-I were seen only with colesevelam monotherapy $(+4 \%)$ and colesevelam plus atorvastatin $(+9 \%)$; the differences among treatment groups were also significant $(p<0.0001)$ [41]. In the simvastatin study, significant increases from baseline in apo A-I were seen with colesevelam alone $(+4 \%$; $p<0.05)$, simvastatin alone $(+5 \% ; p<0.05)$, and 
colesevelam plus simvastatin $(+10 \% ; p<0.0001)$ [42]. Similarly, in the lovastatin study, increases in apo A-I were significant with colesevelam alone $(+8 \% ; p<0.0001)$, lovastatin alone $(+5 \% ; p<0.05)$, and colesevelam plus lovastatin dosed together $(+5 \% ; p<0.05)$, but did not reach statistical significance with colesevelam plus lovastatin dosed apart $(+4 \%)$ [40].

Triglyceride levels generally decreased from baseline with statin monotherapies, increased with colesevelam monotherapy, and remained relatively unchanged with the combination of colesevelam and a statin [40-42], although the reductions with statin monotherapy in the atorvastatin study (atorvastatin 10 or $80 \mathrm{mg} /$ day) led to a significant difference compared with the colesevelam monotherapy and colesevelam plus atorvastatin $10 \mathrm{mg} /$ day groups $(p<0.05)$ [41]. Significant increases in triglyceride levels were reported in patients with type 2 diabetes in two pivotal trials where colesevelam was added to either sulfonylurea- or insulin-based therapy [46, 47]; however, in a third pivotal diabetes trial, triglyceride levels were not significantly increased when colesevelam was added to metformin-based therapy [48].

Some non-lipid parameters also showed findings of interest in these studies. In the pooled analysis of doubleblind, placebo-controlled trials of colesevelam $3.75 \mathrm{~g} /$ day or placebo added to statin therapy, a significant median reduction in high-sensitivity C-reactive protein levels was seen with the addition of colesevelam $(-23.3 \% ; p<0.01)$ [44]. In addition, in the study of colesevelam $3.75 \mathrm{~g} /$ day plus rosuvastatin $5 \mathrm{mg} /$ day or rosuvastatin $10 \mathrm{mg} /$ day alone in patients with hypercholesterolemia and insulin resistance, homeostasis model assessment of insulin resistance index increased in the rosuvastatin monotherapy group and decreased in the combination therapy group, leading to a significant between-group difference $(+15$ vs. $-32 \% ; p<0.05)$.[43]

\subsubsection{Colesevelam Plus Fibrates}

The primary effects of fibrates include reduction of triglycerides (20-50\%) and increases in HDL-C levels (10-20\%); moderate increases in LDL-C (5-20\%) may also be observed, but the effects vary depending on the patient's lipid profile $[1,49]$. One study has evaluated the dual combination of colesevelam and a fibrate.

This randomized, double-blind, placebo-controlled, parallel-group study investigating the efficacy of fenofibrate plus colesevelam $\mathrm{HCl}$ versus fenofibrate monotherapy included a 4- to 8-week washout period followed by an 8 -week run-in period wherein 129 patients with mixed hyperlipidemia were administered fenofibrate $160 \mathrm{mg} /$ day. Patients were then randomized to receive fenofibrate in combination with colesevelam $3.75 \mathrm{~g} /$ day or placebo for 6 weeks [50]. Colesevelam plus fenofibrate produced significantly greater reductions in LDL-C levels than fenofibrate monotherapy from the end of the run-in period to study end $(-10.4$ vs. $+2.3 \% ; p<0.0001)$; effects on apo B were similar ( -7.3 vs. $+0.8 \%$; $p=0.0002)$. There was a slight increase in triglycerides in the combination therapy group and a slight decrease in the fenofibrate monotherapy group $(+5.6$ vs. $-2.6 \%)$, but there was no significant difference between the groups [50]. Similarly, HDL-C levels slightly increased in the combination therapy group and slightly decreased in the fenofibrate monotherapy group $(+0.2$ vs. $-1.1 \%$; $p=0.3854)$. Colesevelam and fenofibrate had additive effects on LDL-C levels, regardless of whether patients' triglyceride levels were $>200 \mathrm{mg} / \mathrm{dL}$. This is relevant for patients with mixed hyperlipidemia, as those with triglyceride levels $>200 \mathrm{mg} / \mathrm{dL}$ often have unchanged or increased LDL-C levels following initiation of fibrate or niacin monotherapy, suggesting a need for treatments that lower both LDL-C and triglyceride levels [50]. It should be noted that colesevelam is contraindicated in patients with triglyceride levels $>500 \mathrm{mg} / \mathrm{dL}$ [51].

\subsubsection{Colesevelam Plus Niacin}

Niacin primarily increases HDL-C levels (15-35\%), and to a lesser extent reduces triglycerides $(20-50 \%)$, with moderate LDL-C-lowering effects (5-25\%) [1]. One recent study evaluated the dual combination of colesevelam and niacin. In the study, adults with dyslipidemia and impaired fasting plasma glucose levels were randomized to receive colesevelam $3.75 \mathrm{~g} / \mathrm{day}(n=70)$ or placebo in addition to niacin ( $n=70$; titrated from $500 \mathrm{mg}$ /day up to a maximum of $2,000 \mathrm{mg} / \mathrm{day}$, based on tolerability) for 12 weeks [52]. Significantly greater reductions in LDL-C were seen with colesevelam compared with placebo $(-20.7$ vs. $-12.9 \% ; p=0.0088)$. In addition, colesevelam was shown to offset the adverse effects of niacin on glucose metabolism; subjects who received colesevelam had significantly smaller increases in fasting plasma glucose (1.8 vs. $6.7 \mathrm{mg} / \mathrm{dL} ; p=0.0046)$ and hemoglobin A1c (0.06 vs. $0.18 \% ; p=0.005)$ compared with those who received placebo [52].

Although colesevelam/niacin combination therapy demonstrated lipid-lowering and metabolic benefits versus the placebo/niacin combination, results of the AIM-HIGH and HPS2-THRIVE studies suggest that the use of niacin in lipid-lowering combination therapy may be limited $[53,54]$. These studies demonstrated that the addition of niacin to a statin had no incremental benefit in reducing cardiovascular events (AIM-HIGH) or the risk of heart attacks, strokes, or operations to open blocked arteries (HPS2-THRIVE) in patients with well-controlled LDL-C 
levels. Furthermore, the unwanted side effects associated with the addition of niacin appeared to outweigh the benefits of its use [53, 54].

\subsubsection{Colesevelam Plus Ezetimibe}

Ezetimibe primarily reduces LDL-C levels $(\sim 19 \%)$, with more modest reductions in triglycerides $(\sim 8 \%)$ and increases in HDL-C $(3 \%)$ in patients with primary (heterozygous familial and non-familial) hypercholesterolemia, as shown by Pandor et al. [55] in a systematic review and meta-analysis of randomized controlled trials comprising 2,722 patients administered ezetimibe monotherapy for a minimum treatment period of 12 weeks. As this was a meta-analysis, the authors noted that although there was no statistical evidence of significant heterogeneity in the assessed trials, differences in patient characteristics or the trial designs between the studies could have potentially influenced the results [55]. Limited studies have been conducted with the dual combination of colesevelam and ezetimibe. A small, double-blind, randomized, paralleldesign pilot study in adults with hypercholesterolemia $(N=20)$ indicated that the incremental LDL-C-lowering effects of adding colesevelam $1.875 \mathrm{~g} /$ day to ezetimibe $10 \mathrm{mg} /$ day for 12 weeks was not statistically significant ( -30 vs. $-24 \% ; p=0.102)$ [56]. The small number of patients in this study and the lack of assurance that patients in the two treatment groups did not differ in some respects were listed as relevant study limitations [56].

However, in a larger multicenter, randomized, doubleblind, placebo-controlled, parallel-group study in 86 adults with primary hypercholesterolemia that was designed to determine the superiority of colesevelam $3.75 \mathrm{~g} /$ day plus ezetimibe $10 \mathrm{mg} /$ day versus ezetimibe alone, a significantly greater reduction in LDL-C was seen with colesevelam plus ezetimibe, compared with ezetimibe monotherapy, for 6 weeks ( -32.3 vs. $-21.4 \%$; $p<0.0001)$ [57]. In addition, subjects receiving colesevelam plus ezetimibe, compared with ezetimibe monotherapy, had a significantly greater reduction in apo B $(-22.7$ vs. $-14.8 \% ; p=0.0001)$ and increase in apo A-I $(+6.7$ vs. $+1.3 \% ; p=0.0036)$. There was a slight increase in triglycerides in the combination therapy group and a slight decrease in the ezetimibe monotherapy group $(+4.9$ vs. $-2.8 \%)$, but there was no significant difference between the groups [57]. Thus, it is possible to achieve LDL-C reductions with this combination that are similar to those seen with low-dose statin monotherapy. A limitation of this study was that levels of ezetimibe were not calculated. Consequently, the study could not assess if colesevelam had an effect on ezetimibe absorption [57]. However, it is noteworthy that the two agents were not coadministered, i.e., ezetimibe was administered at bedtime whereas three tablets of colesevelam were taken with each morning and evening meal or six tablets with the evening meal.

\subsection{Colesevelam in Triple Combinations}

Two studies have evaluated the efficacy of colesevelambased, triple-drug combination lipid-lowering regimens. A randomized, double-blind, partially placebo-controlled, 1 -year study in adults with atherosclerotic disease and dyslipidemia $(N=123)$ evaluated the incremental effects of adding extended-release niacin (titrated from $500 \mathrm{mg} /$ day to $2 \mathrm{~g} /$ day) and colesevelam $3.75 \mathrm{~g} /$ day to atorvastatin $10-80 \mathrm{mg} /$ day [58]. Compared with atorvastatin monotherapy, there was no further reduction in LDL-C with atorvastatin plus niacin ( $-47 \%$ for both), but a significantly greater reduction was achieved with atorvastatin plus niacin plus colesevelam $(-57 \% ; p=0.001)$; a lower average atorvastatin dose was required to meet LDL-C targets with dual and triple therapy. In addition, the triplecombination group, compared with the atorvastatin monotherapy group, had significantly greater reductions in apo B $(-51$ vs. $-40 \% ; p<0.01)$ and triglycerides $(-42$ vs. $-25 \% ; p<0.01)$ and a significantly greater increase in apo A-I $(+15$ vs. $+7 \% ; p=0.01)$. Changes in apo B $(-45 \%)$, triglycerides $(-33 \%)$, and apo A-I $(+11 \%)$ in the dual-combination group were not significantly different from those in the atorvastatin monotherapy group [58].

The addition of colesevelam to stable, maximally tolerated therapy with a statin plus ezetimibe for 12 weeks in adults with familial hypercholesterolemia resulted in significantly greater reductions in LDL-C $(-11.4$ vs. $+0.6 \%$; $p<0.001)$ and apo B ( -6.0 vs. $+4.6 \% ; p=0.01)$ compared with placebo [59]. Triglyceride levels increased in both groups, resulting in no significant between-group difference. An unexpected finding was that hemoglobin A1c was significantly reduced in patients receiving colesevelam as compared with placebo (least-squares mean treatment difference $-0.12 \% ; p<0.05)$. The patients' mean baseline hemoglobin A1c of 5.7-5.8\% suggests that many were at high risk for development of new-onset type 2 diabetes [59].

\section{Safety and Tolerability}

Colesevelam, which is not systemically absorbed, was generally well tolerated when added to other lipid-lowering therapies [40-42, 50, 57, 59]. Adverse event profiles were similar to the comparators, apart from a slight increase in gastrointestinal adverse events such as constipation in 
some studies $[40,50,57,59]$. Statistical significance was assessed and showed no differences in the incidence of constipation in the lovastatin combination study (placebo, $4 \%$; colesevelam monotherapy, $10 \%$; lovastatin monotherapy, $0 \%$; colesevelam plus lovastatin dosed together, $7 \%$; colesevelam plus lovastatin dosed apart, $4 \%$ ) [40], and the study assessing the triple combination of colesevelam, ezetimibe, and a statin (colesevelam, $9 \%$; placebo, $5 \%$ ) [59].

Colesevelam has a low propensity for drug-drug interactions, and those that occur can typically be minimized by staggering drug administration by $4 \mathrm{~h}$ [60-63]. Notably, although drug-drug interactions with a number of lipidlowering therapies (including simvastatin, fluvastatin, gemfibrozil, and ezetimibe) have been reported with the first-generation bile acid sequestrants [64-67], colesevelam has been shown to have no pharmacokinetic drug-drug interactions with lovastatin or fenofibrate [68, 69].

It should be noted that the colesevelam prescribing information states that the use of colesevelam is contraindicated in patients with triglyceride levels $>500 \mathrm{mg} / \mathrm{dL}$, and that colesevelam should be discontinued if triglycerides exceed $500 \mathrm{mg} / \mathrm{dL}$ or if the patient develops hypertriglyceridemia-induced pancreatitis [51].

\section{Conclusions}

Colesevelam has additive cholesterol-lowering effects when used in combination with other lipid-lowering therapies. This is relevant to not only patients who are resistant or intolerant to statins, but also patients with mixed hyperlipidemia. In some patient populations, the additional glucose-lowering effect of colesevelam may be beneficial in offsetting hyperglycemic effects of other lipid-lowering drugs. The effect of colesevelam on cardiovascular morbidity and mortality has not been established. Colesevelam is generally well tolerated, with a low potential for systemic metabolic drug-drug interactions. More research is needed with combination therapy, including combinations with colesevelam.

Acknowledgments Sushma Soni of inScience Communications, Springer Healthcare, provided medical writing support funded by Daiichi Sankyo, Inc. Oliseyenum M. Nwose, MBBS, MRCPath, is employed by Daiichi Sankyo, Inc., and Michael R. Jones, PhD, was previously employed by Daiichi Sankyo, Inc. All authors provided scientific interpretation of the data, provided substantive contributions to the manuscript, and approved the final draft of the submission.

Open Access This article is distributed under the terms of the Creative Commons Attribution Noncommercial License which permits any noncommercial use, distribution, and reproduction in any medium, provided the original author(s) and the source are credited.

\section{References}

1. National Cholesterol Education Program Expert Panel on Detection, Evaluation and Treatment of High Blood Cholesterol in Adults (Adult Treatment Panel III). Third Report of the National Cholesterol Education Program (NCEP) Expert Panel on Detection, Evaluation, and Treatment of High Blood Cholesterol in Adults (Adult Treatment Panel III) final report. Circulation. 2002;106(25):3143-421.

2. Grundy SM, Cleeman JI, Merz CNB, Brewer HB Jr, Clark LT, Hunninghake DB, et al; for the Coordinating Committee of the National Cholesterol Education Program. Implications of recent clinical trials for the National Cholesterol Education Program Adult Treatment Panel III guidelines. Circulation. 2004;110(2): 227-39.

3. Goodman DS, Hulley SB, Clark LT, Davis CE, Fuster V, LaRosa JC, et al. Report of the National Cholesterol Education Program Expert Panel on Detection, Evaluation, and Treatment of High Blood Cholesterol in Adults. Arch Intern Med. 1988;148(1):36-69.

4. Gherondache $\mathrm{CN}$, Pincus G. Metabolic changes induced in elderly patients with a cholesterol lowering resin, cholestyramine. Metabolism. 1964;13:1462-8.

5. Hashim SA, Vanitallie TB. Cholestyramine resin therapy for hypercholesteremia: clinical and metabolic studies. JAMA. 1965;192:289-93.

6. Casdorph HR. Hypercholesteremia-treatment with cholestyramine, a bile acid sequestering resin. Calif Med. 1967;106(4): $293-5$.

7. Glueck CJ, Ford S, Scheel D, Steiner P. Colestipol and cholestyramine resin. Comparative effects in familial type II hyperlipoproteinemia. JAMA. 1972;222:676-81.

8. Ryan JR, Jain A. The effect of colestipol or cholestyramine on serum cholesterol and triglycerides in a long-term controlled study. J Clin Pharmacol New Drugs. 1972;12(7):268-73.

9. Parkinson TM, Gundersen K, Nelson NA. Effects of colestipol (U-26,597A), a new bile acid sequestrant, on serum lipids in experimental animals and man. Atherosclerosis. 1970;11(3): $531-7$.

10. Lipid Research Clinics Program. The Lipid Research Clinics Coronary Primary Prevention Trial results. I. Reduction in incidence of coronary heart disease. JAMA. 1984;251(3):351-64.

11. Angelin B, Eriksson M, Einarsson K. Combined treatment with cholestyramine and nicotinic acid in heterozygous familial hypercholesterolaemia: effects on biliary lipid composition. Eur J Clin Invest. 1986;16(5):391-6.

12. Kane JP, Malloy MJ, Tun P, Phillips NR, Freedman DD, Williams ML, et al. Normalization of low-density-lipoprotein levels in heterozygous familial hypercholesterolemia with a combined drug regimen. N Engl J Med. 1981;304(5):251-8.

13. Lipid Research Clinics Program. The Lipid Research Clinics Coronary Primary Prevention Trial results. II. The relationship of reduction in incidence of coronary heart disease to cholesterol lowering. JAMA. 1984;251(3):365-74.

14. Shepherd J, Cobbe SM, Ford I, Isles CG, Lorimer AR, Macfarlane PW, for the West of Scotland Coronary Prevention Study Group, et al. Prevention of coronary heart disease with pravastatin in men with hypercholesterolemia. $\mathrm{N}$ Engl $\mathrm{J}$ Med. 1995;333(20):1301-7.

15. Scandinavian Simvastatin Survival Study Group. Randomised trial of cholesterol lowering in 4444 patients with coronary heart disease: the Scandinavian Simvastatin Survival Study (4S). Lancet. 1994;344(8934):1383-9.

16. Pearson TA, Laurora I, Chu H, Kafonek S. The Lipid Treatment Assessment Project (L-TAP): a multicenter survey to evaluate the 
percentages of dyslipidemic patients receiving lipid-lowering therapy and achieving low-density lipoprotein cholesterol goals. Arch Intern Med. 2000;160(4):459-67.

17. Yan AT, Yan RT, Tan M, Hackam DG, Leblanc KL, Kertland H, The Vascular Protection (VP) and Guidelines Oriented Approach to Lipid Lowering (GOALL) Registries Investigators, et al. Contemporary management of dyslipidemia in high-risk patients: targets still not met. Am J Med. 2006;119(8):676-83.

18. Bożentowicz-Wikarek M, Kocełak P, Smertka M, OlszaneckaGlinianowicz M, Chudek J. Effectiveness of lipid-lowering therapy with statins for secondary prevention of atherosclerosisguidelines vs. reality. Pharmacol Rep. 2012;64(2):377-85.

19. Robinson JG, Ballantyne CM, Hsueh W, Rosen J, Lin J, Shah A, et al. Achievement of specified low-density lipoprotein cholesterol, non-high-density lipoprotein cholesterol apolipoprotein B, and high-sensitivity C-reactive protein levels with ezetimibe/ simvastatin or atorvastatin in metabolic syndrome patients with and without atherosclerotic vascular disease (from the VYMET study). J Clin Lipidol. 2011;5(6):474-82.

20. Kotseva K, Wood D, De Backer G, De Bacquer D, Pyörälä K, Keil U, for the EUROASPIRE Study Group, et al. Cardiovascular prevention guidelines in daily practice: a comparison of EUROASPIRE I, II, and III surveys in eight European countries. Lancet. 2009;373(9667):929-40.

21. Kotseva K, Wood D, De Backer G, EUROASPIRE Study Group, et al. EUROASPIRE III. Management of cardiovascular risk factors in asymptomatic high-risk patients in general practice: cross-sectional survey in 12 European countries. Eur J Cardiovasc Prev Rehabil. 2010;17(5):530-40.

22. Mammen AL, Amato AA. Statin myopathy: a review of recent progress. Curr Opin Rheumatol. 2010;22(6):644-50.

23. Egan A, Colman E. Weighing the benefits of high-dose simvastatin against the risk of myopathy. N Engl J Med. 2011; 365(4):285-7.

24. Golomb BA, Evans MA. Statin adverse effects: a review of the literature and evidence for a mitochondrial mechanism. Am J Cardiovasc Drugs. 2008;8(6):373-418.

25. Cham S, Evans MA, Denenberg JO, Golomb BA. Statin-associated muscle-related adverse effects: a case series of 354 patients. Pharmacotherapy. 2010;30(6):541-53.

26. Silva M, Matthews ML, Jarvis C, Nolan NM, Belliveau P, Malloy $\mathrm{M}$, et al. Meta-analysis of drug-induced adverse events associated with intensive-dose statin therapy. Clin Ther. 2007;29(2):253-60.

27. Study of the Effectiveness of Additional Reductions in Cholesterol Homocysteine Collaborative Group. Intensive lowering of LDL cholesterol with $80 \mathrm{mg}$ versus $20 \mathrm{mg}$ simvastatin daily in 12 064 survivors of myocardial infarction: a double-blind randomised trial. Lancet. 2010;376(9753):1658-69.

28. Cholesterol Treatment Trialists' (CTT) Collaborators. The effects of lowering LDL cholesterol with statin therapy in people at low risk of vascular disease: meta-analysis of individual data from 27 randomised trials. Lancet. 2012;380(9841):581-90.

29. Mansi I, Frei CR, Pugh MJ, Makris U, Mortensen EM. Statins and musculoskeletal conditions, arthropathies, and injuries [published online ahead of print June 3, 2013]. JAMA Intern Med. doi:10.1001/jamainternmed.2013.6184.

30. Sattar N, Preiss D, Murray HM, Welsh P, Buckley BM, de Craen AJM, et al. Statins and risk of incident diabetes: a collaborative meta-analysis of randomised statin trials. Lancet. 2010; 375(9716):735-42.

31. Zaharan NL, Williams D, Bennett K. Statins and risk of treated incident diabetes in a primary care population. Br J Clin Pharmacol. 2013;75(4):1118-24.

32. Danaei G, García Rodríguez LA, Fernandez Cantero O, Hernán MA. Statins and risk of diabetes: an analysis of electronic medical records to evaluate possible bias due to differential survival. Diabetes Care. 2013;36(5):1236-40.

33. Waters DD, Ho JE, Boekholdt SM, DeMicco DA, Kastelein JJP, Messig M, et al. Cardiovascular event reduction versus new-onset diabetes during atorvastatin therapy: effect of baseline risk factors for diabetes. J Am Coll Cardiol. 2013;61(2):148-52.

34. Preiss D, Seshasai SRK, Welsh P, Murphy SA, Ho JE, Waters $\mathrm{DD}$, et al. Risk of incident diabetes with intensive-dose compared with moderate-dose statin therapy: a meta-analysis. JAMA. 2011;305(24):2556-64.

35. Rautio N, Jokelainen J, Oksa H, Saaristo T, Peltonen M, Vanhala $\mathrm{M}$, et al. Do statins interfere with lifestyle intervention in the prevention of diabetes in primary healthcare? One-year follow-up of the FIN-D2D project. BMJ Open. 2012;2(5):e001472.

36. Sharma M, Ansari MT, Abou-Setta AM, Soares-Weiser K, Ooi TC, Sears M, et al. Systematic review: comparative effectiveness and harms of combination therapy and monotherapy for dyslipidemia. Ann Intern Med. 2009;151(9):622-30.

37. American Diabetes Association. Standards of medical care in diabetes-2013. Diabetes Care. 2013;36(Suppl 1):S11-66.

38. Reiner Ž, Catapano AL, De Backer G, et al. ESC/EAS guidelines for the management of dyslipidaemias. The Task Force for the management of dyslipidaemias of the European Society of Cardiology (ESC) and the European Atherosclerosis Society (EAS). Eur Heart J. 2011;32:1769-818.

39. Reiner $\breve{Z}$. Combined therapy in the treatment of dyslipidemia. Fundam Clin Pharmacol. 2010;24(1):19-28.

40. Davidson MH, Toth P, Weiss S, McKenney J, Hunninghake D, Isaacsohn $\mathrm{J}$, et al. Low-dose combination therapy with colesevelam hydrochloride and lovastatin effectively decreases lowdensity lipoprotein cholesterol in patients with primary hypercholesterolemia. Clin Cardiol. 2001;24(6):467-74.

41. Hunninghake D, Insull W Jr, Toth P, Davidson D, Donovan JM, Burke SK. Coadministration of colesevelam hydrochloride with atorvastatin lowers LDL cholesterol additively. Atherosclerosis. 2001;158(2):407-16.

42. Knapp HH, Schrott H, Ma P, Knopp R, Chin B, Gaziano JM, et al. Efficacy and safety of combination simvastatin and colesevelam in patients with primary hypercholesterolemia. Am J Med. 2001;110(5):352-60.

43. Florentin M, Liberopoulos EN, Rizos CV, Kei AA, Liamis G, Kostapanos MS, et al. Colesevelam plus rosuvastatin $5 \mathrm{mg} /$ day versus rosuvastatin $10 \mathrm{mg} /$ day alone on markers of insulin resistance in patients with hypercholesterolemia and impaired fasting glucose. Metab Syndr Relat Disord. 2013;11(3):152-6.

44. Bays HE, Davidson M, Jones MR, Abby SL. Effects of colesevelam hydrochloride on low-density lipoprotein cholesterol and high-sensitivity C-reactive protein when added to statins in patients with hypercholesterolemia. Am J Cardiol. 2006;97(8): 1198-205.

45. Jialal I, Abby SL, Misir S, Nagendran S. Concomitant reduction in low-density lipoprotein cholesterol and glycated hemoglobin with colesevelam hydrochloride in patients with type 2 diabetes: a pooled analysis. Metab Syndr Relat Disord. 2009;7(3):255-8.

46. Fonseca VA, Rosenstock J, Wang AC, Truitt KE, Jones MR. Colesevelam $\mathrm{HCl}$ improves glycemic control and reduces LDL cholesterol in patients with inadequately controlled type 2 diabetes on sulfonylurea-based therapy. Diabetes Care. 2008;31(8): 1479-84.

47. Goldberg RB, Fonseca VA, Truitt KE, Jones MR. Efficacy and safety of colesevelam in patients with type 2 diabetes mellitus and inadequate glycemic control receiving insulin-based therapy. Arch Intern Med. 2008;168(14):1531-40.

48. Bays HE, Goldberg RB, Truitt KE, Jones MR. Colesevelam hydrochloride therapy in patients with type 2 diabetes mellitus 
treated with metformin: glucose and lipid effects. Arch Intern Med. 2008;168(18):1975-83.

49. Chapman MJ. Fibrates: therapeutic review. Br J Diabetes Vasc Dis. 2006;6(1):11-20.

50. McKenney J, Jones M, Abby S. Safety and efficacy of colesevelam hydrochloride in combination with fenofibrate for the treatment of mixed hyperlipidemia. Curr Med Res Opin. 2005;21(9):1403-12.

51. Welchol [package insert]. Parsippany, NJ: Daiichi-Sankyo, Inc.; 2013.

52. Davidson MH, Rooney M, Pollock EM, Drucker JL, Choy Y. The effect of colesevelam and niacin on low-density lipoprotein cholesterol and plasma glucose (abstr.). Circulation. 2012;126(21 Suppl):A11700.

53. The AIM-HIGH Investigators. Niacin in patients with low HDL cholesterol levels receiving intensive statin therapy. N Engl J Med. 2011;365(24):2255-67.

54. HPS2-THRIVE (Treatment of HDL to Reduce the Incidence of Vascular Events). http://www.thrivestudy.org. Accessed 21 June 2013.

55. Pandor A, Ara RM, Tumur I, Wilkinson AJ, Paisley S, Duenas A, et al. Ezetimibe monotherapy for cholesterol lowering in 2,722 people: systematic review and meta-analysis of randomized controlled trials. J Intern Med. 2009;265(5):568-80.

56. Knopp RH, Tsunehara C, Retzlaff BM, Fish B, Nguyen H, Anderson S, et al. Lipoprotein effects of combined ezetimibe and colesevelam hydrochloride versus ezetimibe alone in hypercholesterolemic subjects: a pilot study. Metabolism. 2006;55(12): 1697-703.

57. Bays H, Rhyne J, Abby S, Lai Y-L, Jones M. Lipid-lowering effects of colesevelam $\mathrm{HCl}$ in combination with ezetimibe. Curr Med Res Opin. 2006;22(11):2191-200.

58. Moore A, Phan BAP, Challender C, Williamson J, Marcovina S, Zhao X-Q. Effects of adding extended-release niacin and colesevelam to statin therapy on lipid levels in subjects with atherosclerotic disease. J Clin Lipidol. 2007;1(6):620-5.

59. Huijgen R, Abbink EJ, Bruckert E, Stalenhoef AFH, Imholz BPM, Durrington PN, for the Triple Study Group, et al. Colesevelam added to combination therapy with a statin and ezetimibe in patients with familial hypercholesterolemia: a 12-week, multicenter, randomized, double-blind, controlled trial. Clin Ther. 2010;32(4):615-25.

60. Brown KS, Armstrong IC, Wang A, Walker JR, Noveck RJ, Swearingen D, et al. Effect of the bile acid sequestrant colesevelam on the pharmacokinetics of pioglitazone, repaglinide, estrogen estradiol, norethindrone, levothyroxine, and glyburide. J Clin Pharmacol. 2010;50(5):554-65.

61. Donovan JM, Stypinski D, Stiles MR, Olson TA, Burke SK. Drug interactions with colesevelam hydrochloride, a novel, potent lipid-lowering agent. Cardiovasc Drugs Ther. 2000;14(6): 681-90.

62. Wickremasingha $\mathrm{P}, \mathrm{He} \mathrm{L}$, Lee J, Tao B, Mendell-Harary J, Walker J, et al. Lack of effect of colesevelam $\mathrm{HCl}$ on the singledose pharmacokinetics of aspirin, atenolol, enalapril, phenytoin, rosiglitazone, and sitagliptin. Parsippany, NJ: Daiichi Sankyo, Inc., 2013. (Data on file).

63. He L, Wickremasingha P, Lee J, Tao B, Mendell-Harary J, Walker J, et al. The effects of colesevelam $\mathrm{HCl}$ on the single-dose pharmacokinetics of glimepiride, extended-release glipizide, and olmesartan medoxomil. Parsippany, NJ: Daiichi Sankyo, Inc., 2013. (Data on file).

64. Nakai A, Nishikata M, Matsuyama K, Ichikawa M. Drug interaction between simvastatin and cholestyramine in vitro and in vivo. Biol Pharm Bull. 1996;19(9):1231-3.

65. Kosoglou T, Statkevich P, Reyderman L, Pember LJC, Maxwell SE, Courtney R, et al. Effects of selected drugs on exposure to ezetimibe (abstr.). Eur Heart J. 2003;24(suppl):462.

66. Smith HT, Jokubaitis LA, Troendle AJ, Hwang DS, Robinson WT. Pharmacokinetics of fluvastatin and specific drug interactions. Am J Hypertens. 1993;6(11 Pt 2):375S-82S.

67. Forland SC, Feng Y, Cutler RE. Apparent reduced absorption of gemfibrozil when given with colestipol. J Clin Pharmacol. 1990;30(1):29-32.

68. Donovan JM, Kisicki JC, Stiles MR, Tracewell WG, Burke SK. Effect of colesevelam on lovastatin pharmacokinetics. Ann Pharmacother. 2002;36(3):392-7.

69. Jones MR, Baker BA, Mathew P. Effect of colesevelam $\mathrm{HCl}$ on single-dose fenofibrate pharmacokinetics. Clin Pharmacokinet. 2004;43(13):943-50. 